\title{
Residential Environmental Livability in Nigeria: An Overview
}

\author{
Sunusi Bashari \\ Ahmad Hariza Hashim \\ Department of Resource Management and Consumer Studies \\ Faculty of Human Ecology \\ Universiti Putra Malaysia \\ Asnarulkhadi Abu Samah \\ Nobaya Ahmad \\ Department of Social and Development Sciences \\ Faculty of Human Ecology \\ Universiti Putra Malaysia
}

\begin{abstract}
Purpose - The purpose of this paper is to examine the problems of public low-cost housing in Nigeria in relation to residents' well-being and suggest some guiding principles that can be used for successful public low-cost housing for low-income people in Nigeria.

Design/methodology/approach - This research was conducted through in-depth reviews of previous literatures and document related to public low-cost housing in Nigeria. National housing policy is among the document analyzed by the researcher.

Findings - The major constraints to public low-cost housing in Nigeria is that, the housing units does not reflect the culture of the resident. Most of the residents are not satisfied with it. The housing units are characterized by indecent housing units, the needs and aspirations of the residents are neglected, high safety and security challenges, poor locational and difficult to access functional facilities.

Research limitation / implications - The main limitation of this research is no field survey or interview to collect data from the residents of public low-cost housing has been conducted.

Practical Implications - This research will assist housing policy makers and housing developers to understand the important of opinion or views of beneficiaries before and after construction of public low-cost housing. This will be achieve if certain attributes of housing are incorporated in the National Housing Policy as may be suggested by the beneficiaries.

Significant to developing countries- Recent studies in Nigeria have shown that, the quality level of building and infrastructural elements depend on cultural background of the beneficiaries. Presently, scholars in Nigeria are shifting towards housing design that will reflect the desire and expectations of beneficiaries through incorporating of culture of the people in housing design. This issue is of great significant to developing countries with different cultural diversities, these differences in culture need to be considered in housing design not adopting standard from developed world.

Originality / value - The findings of this paper was based on reviewed of earlier studies on residential environmental livability particularly the public low-cost housing in Nigeria and the analysis of document of National Housing Policy 2012. The findings of this study revealed some guiding principles that can help in solving public low-cost housing problems in Nigeria.
\end{abstract}

Keywords - Housing, public low-cost housing, residential livability, residents' well-being, culture, housing policy, preferences, low-income,

\section{Introduction}

There are numerous meanings attached to housing. Housing is literally seen as buildings, shelters, homes, a dwelling place where people live (Kalu, Agbarakwe, \& Anowor, 2014). Housing is also a basic necessity of life just like food and clothing where every human being must be provided with it (Festus \& Amos, 2015).

Most of low-income earners in Nigeria live in substandard and poor quality housing, because access to quality housing is far beyond the economic reach of the majority of the citizen (Makinde, 2014). The situation led to high rate of housing shortage in terms of quantity and quality both in rural and urban centers. 
The problems attached to rural areas is basically related to poor quality housing and environment while in urban centers they faced with deficiency in terms of quantity of housing stock needed and the quality available dwelling (Makinde, 2014; Abiodun Olukayode Olotuah, 2016).

In order to meet the demand for the houses for the low-income earners in Nigeria, various government strategies such as the design and construction of low-cost houses for low-income earners began in 1979 (Abiodun Olukayode Olotuah, 2015). The program consisted of 1-bedroom core houses for low-income earners, which could be extended by the owner if the need arose and 3-bedroom apartments for other income groups. These have been introduced by the government in their attempt towards solving serious shortage of houses through different housing reform programmes. Currently, there are several housing delivery programmes like the affordable housing scheme targeting low-income people, private partnership effort and many private finance initiative models designed to provide for about $3 \%$ of the required stock (Makinde, 2014). But, the programmes were not sustainable over time due to the absence of a postimplementation strategy, as an essential part of the management system, and still little or no success were recorded. There are important information that need to be gathered on socio-economic aspects of the users before construction of public housing schemes and after the construction certain information are also vital in giving supporting evidence which can be used to judge the performance of public housing schemes (Eziyi O. Ibem \& Amole, 2010; Makinde, 2014).

Jansen (2012) explained that, residential preference referred to relative attractiveness to house by individual. This concept of preference became an important issue in housing studies because it gives clear image of households' priority for particular housing attributes. Thus, understanding the preference of housing will help in making housing policy and framework for future housing environment especially housing for the poor (Khozaei, Ramayah, Hassan, \& Surienty, 2012). Apart from quantity or adequacy of low-income housing, also the people's perception about the places that are currently live especially to find out what make their neighborhood a good place or bad place or livability is equally important (Leby \& Hashim, 2010).

\section{Study area}

Nigeria is one of the 16 West African countries with total land area of about 9, 23, $768 \mathrm{~km}^{2}$. The country is divided into 36 states with 774 local government areas. Among the African countries, Nigeria is the most populous country estimated to have a population of 174 million people and over 250 ethnic groups. In 2013, International Monetary Fund World Outlook Database, using Gross Domestic Product (GDP) based on Purchasing Power Parity (PPP) per capita, indicated that Nigeria was $44^{\text {th }}$ of the poorest listed countries with less than $\$ 3000$ (Ajayi, 2015).

In Nigeria, statistics has shown that over 7 out of every 10 people live below the minimum poverty level and 9 of every 10 are in the low-income group (Fadairo \& Olotuah, 2013). This indicates that, these people cannot provide housing for themselves, they need intervention from government through public low-cost housing.

\section{Methodology}

The main methodology adopted in this study are the review of relevant literatures and document. The document isa formal document which compiled the sufficient data relevant to this study, for instance, National housing policy of Nigeria. Some of the literatures are inform of expressing the recent actual condition of public low-cost housing and the problems associated with public low-cost housing in Nigeria.

\section{Public Low-Cost Housing in Nigeria}

Makinde (2014) stated that housing provision in Nigeria is mainly directed to middle- and high-income population that can either pay cash or access mortgage finance from the banks. While the majority of the population who are lowincome earners proposes some ways out to call for developers, investors and scholars if they can assist them to get out of terrible condition. In addition, housing market becomes difficult to the reach of low-income where by the house prices and rents have grown ahead of inflation. The situation became worse when the composition of houses for sale and rent on the market has been inexorably shifting towards very expensive home (Nubi, 2008).

According to Eziyi O. Ibem and Amole (2012)if the poor are considered to be incapable of helping themselves, then they have to be helped. In housing context this tends to mean that only government are capable of building satisfactory housing for the low-income. In this regard, public low-cost housing is the only alternative to provide houses to lowincome people expected to be affordable to them, and their problems will be solved. Nigerian government have realized that there are housing problems as stated earlier, that was the main reasons many of the housing policies, strategies, programmes have emerged from colonial era to date. Currently, Nigeria is using 2012 National housing policy which was promulgated in an attempt to provide solutions to housing problems (Festus \& Amos, 2015). 
The policy emphasizes on most aspects affecting the low income groups regarding housing by devoting the whole chapter to them and highlighted problems specifically affecting low-income earners. The main objective of this housing policy is to ensure all Nigerians particularly low-income earners, have access to affordable housing, decent accommodation and live in a livable environment (NHP, 2012; Olawale et al., 2015).

\section{Problems faced by the public low-cost housing Beneficiaries}

\subsection{The Needs, Aspirations and Preferences of Beneficiaries Neglected}

The views of targeted people tend to be neglected, this is because their needs, aspirations and preferences in terms of what they should have and order of their priorities are not considered before construction of the houses. Thus, must of structural aspects of the housing units are not being satisfied (Ayoola \& Amole, 2014). Therefore, if opinion of the people in terms of needs and aspirations are not considered, this could later influence their well-being.

\subsection{Indecent houses}

The residents of most of public low-cost housing in Nigeria have little or absent of basic infrastructural and social amenities, such as water and electricity, this situation make the housing units not livable and indecent residential environment (Ugonabo \& Emoh, 2013). Thus, indecent houses will lead to poor living conditions which eventually will affect the well-being of the residents.

\subsection{Safety and security challenges}

Mohit and Iyanda (2017) revealed that, most of residents of public low-cost housing in Niger state, Nigeria have shown their dissatisfaction with safety and security situation in and around their residential area. Services, such as police station, fire service were not available close to the residential area.

\subsection{Poor locational and accessibility of functional facilities}

The residents of public low-cost housing in Niger State, Nigeria wanted to have facilities such as schools, hospitals and markets close to their residential environment. But most of these functional facilities were located far away from their residential area. This situation make the residents' children to suffer from high risk of being illiterate and poor health care delivery (Mohit \& Iyanda, 2017).

Therefore, if residents are subjected to these problems, their well-being will certainly be affected in many ways, because the residential livability influences well-being. This can be described through the relationship between the residential livability and residents' well-being in public low-cost housing in Nigeria.

\section{Review of Residential environmental livability and Residents' well-being in public low-cost housing in Nigeria}

\subsection{Residential livability}

According to livable housing Australia, Australia (2012), livable houses are dwellings that guarantee all occupants' quality of life at all life stages; especially easily accessible, cost-effective, navigate inside and around, easy adaptation; and occupants' changing needs responsive. In addition, Lukuman, Sipan, Raji, and Aderemi (2017) viewed livable housing as pre-condition for improving quality of life, healthy living and a critical to economic and social survival. In addition, livable housing combines numerous basic aspects of housing that are mainly depend on environment, cultural, social and economic conditions within the locality. The social viewpoints of housing livability indicators are employments, education and safety, while the environmental aspects indicators include clean air, a noiseless neighborhood, green spaces and an attractive street scene (Panagopoulos, Duque, \& Dan, 2016).

\subsection{Perception of Residential Livability}

To construct a public low-cost housing, understanding of livability from the perspective of the residents is necessary to create the desired livable conditions in residential areas. As such livability, therefore, needs to be examined across various demographic and economic strata of society (Leby \& Hashim, 2010; Pandey, Garg, \& Bharat, 2014). Some researchers on housing have associated the concept of livability to many factors such as; safety, life quality, health, services accessibilities, comfort, living cost, air quality, living standards, transport/mobility and social involvement (Bishop \& Syme, 1995; Howley, Scott, \& Redmond, 2009). Therefore, to increase livability of a residential environment there should be provision of authentic amenities to support social and commercial activities, which are very much relevant to the well-being of the residents of a particular environment (Chun-Hao \& Tsai, 2013).

However, the perception of residents on public low-cost housing livability attributes differ depending on people, time and location (Pandey et al., 2014). 
For instance, According to Lukuman et al. (2017)the perception of residential livability attributes in Nigeria by people in Osun State indicated that, attributes such as nearness to shopping complex and nearness to the market were the most important ranked $1^{\text {st }}$ and $2^{\text {nd }}$ respectively under public amenities related attributes out of 92 attributes ranking using Relative Importance Index. Other attributes that were found to be the most important by the residents were nearness to bathroom and nearness to family which ranked $3^{\text {rd }}$ and $4^{\text {th }}$ respectively while the $5^{\text {th }}$ positioned in the ranking was feeling safe under safety and security related attributes. Similarly, Ukoha and Beamish (1997) stated that the inhabitants of public housing in Abuja, Nigeria identified neighborhood facilities such as schools, hospitals, markets and distance to the place of work as the most important facilities needed by the residents.

\subsection{Residential Livability and Residents' Well-being}

Residential livability referred to satisfaction with one's living set up available at one's housing unit and the neighborhood to the extent that, this satisfaction contribute to the sense of well-being in seven major life domains, such as social, family, safety/health, personal/education development, culture/leisure/arts, financial and work, which at the end contribute to the overall sense of subjective well-being (Sirgy, 2016).

According to Ismail, Jabar, Janipha, and Razali (2015) pointed out that, residential environment become livable if residents are provided with basic needs such as health facilities, recreational center and open green areas, which eventually lead to improvement of subjective well-being of the residents. Housing estates to be provided with an important component such as neighborhood facilities like schools, hospitals, shopping mall and public facilities like roads will affect feeling of general well-being of a household (White \& Schollaert, 1993).

\subsection{Dwelling unit features and Residents' Well-being}

The result of the study of Mohit and Iyanda (2015) in Nigeria, indicated that, although the respondents are living in two and three bedrooms, but they preferred four bedroom. Mohit, Ibrahim, and Rashid (2010) stated that in most cases households make their judgments on residential conditions based on their aspirations and needs. Most of low-income earners in Nigeria live in substandard and poor quality housing, because access to quality housing is far beyond the economic reach of the majority of the citizen (Makinde, 2014). Thus, most of structural aspects of the housing units are not being satisfied (Ayoola \& Amole, 2014). The situation led to high rate of housing shortage in terms of quantity and quality both in rural and urban centers.

If housing units do not provide facilities and amenities that are expected by the residents, such conditions will generate stress in parents, increase mental health problems, and reduces the normal family activities as such will affect children's socio-emotional functioning (Lynch \& Kull, 2013).

\subsection{Physical environment and Residents' Well-being}

The physical environment that are associated with livable housing include; space where people live, work, play area, parking area, prayer hall, pedestrian and walkways (Mohit \& Iyanda, 2015). Public services in residential areas provide conditions for living, these consists of administrative services, security and infrastructure. These increases the societal well-being and development of the community (Bayulken \& Huisingh, 2015). Findings from Baur and Tynon (2010) indicated that physical environment such as play area, parks, green spaces positively influences the well-being of communities in terms of nature-based recreation, health improvements and socialization. In Nigeria, Ebiaride and Umeh (2015) observed that residents living at private housing estate have higher and better satisfaction from the physical and social elements than those living at public housing estate, this is because the type and number of facilities provided at private housing estate are not present in public housing estates.

\subsection{Social Environment and Residents Well-being}

In their research on perceptions on residential environments for urban low-income elderly homeowners aging in place Lee, Kim, Parrott, Giddings, and Robinson (2017) revealed that, low-income aging homeowners liked their neighborhood because of good neighbors' relationship ranging from helping each other to quite environment, friendly neighborhood and privacy. On the other hand, they were most likely to dislike their neighborhood if it was a noisy, an unfriendly neighborhood, lacking maintenance or safety. While, friendliness levels among the respondents were the most and least attribute for the neighborhood.

The level of subjective well-being tend to be higher when individuals have large number of friends and family members, therefore, individuals who have higher well-being tend to have more supportive social relationships and closer than individuals with low baseline life satisfaction. In addition, people tend to be happier when they associate themselves with other people (Diener \& Ryan, 2015). Social interaction and contacts are the most critical factors in shaping the overall well-being and happiness of individuals (Delmelle, Haslauer, \&Prinz, 2013). 


\subsection{Safety and Crime Attributes}

The relationship between the environment and the way an individual interacts with it on daily basis indicates various aspects of associations such as relationship of neighborhood social environment like noise, accidents, safety, security control as well as physical environment such as pollution, traffic, transportation, climate and recreational opportunities which all these have impacts on stress and somatic or psychological problems. It is confirmed every individual wishes to live in a free crime and safe neighborhood. Unsafe environment is said to be a neighborhood with high rate of crime (Leby \& Hashim, 2010). But, it has being documented that many public low-cost housing in Nigeria lack safety and security. For instance, Mohit and Iyanda (2017) revealed that, most of residents of public low-cost housing in Niger state, have shown their dissatisfaction with safety and security situation in and around their residential area. Services, such as police station, fire service were not available close to the residential area.

\subsection{Functional environment and Residents Well-being}

According to Pandey et al. (2014) Functional environment refers to shops, schools, hospitals, markets, bus station and work place in relation to their distances to the town center. Chun-Hao and Tsai (2013) viewed functional environment convenience as the sum of amenities of the community that support needs of residents in a daily life. As such location of housing should be close to wider infrastructure, such as schools, job places, shops and services, so that residents can easily be accessed them by transportation (Gooding, 2016). In Niger State, Nigeria, Mohit and Iyanda (2017) pointed out that respondents of public low-cost housing indicated low satisfaction with neighborhood facilities such as schools and hospitals around the housing estates. In addition, Asiyanbola, Raji, and Shaibu (2012) stated that most of public essential facilities and social amenities were not in good conditions to support human well-being at Ago-Iwoye and Ijebu-Igbo housing estates both located in Ogun State, Nigeria.

\subsection{Socio-economic status and Residents Well-being}

Pandey et al. (2014), Eurofound (2013) and Li, Sun, and Jones (2012) reveled that, socio-economic and demographic parameters have significant bearing on perception of livability, especially attributes like "income", "occupation", "gender" and "working status". Others are age, education, marital status and family size. Livability is perceived and understood differently by different sub-groups of these socio-economic parameters through of few livability attributes which remains the same across various sub-groups. Socio-economic conditions is regarded as one of major factors that determines housing decision-making in terms of housing types and neighborhood (Akinyode, Khan, \& Ahmad, 2015). The study of socio-economic factors in measuring the demand for residential neighborhood in Nigeria, identified educational level, employment, official status and overall monthly income of people in Ibadan contributed in their decision to demand for residential neighborhood and live in Ibadan urban center (Akinyode et al., 2015). In the their research Mohit and Iyanda (2015) found out that, the main factors that influenced the respondents' perception of livability of their housing environment in Niger State are age and employment status.

\subsection{Socio-Cultural characteristics and subjective well-being}

Rapoport (2001) viewed components of culture should comprises of worldviews (expectations, standards, values, norms, rules and meanings), social network, kinship and kinship relations, and family structure. Rapoport (2001) confirmed that these components have influence in shaping or forming the built environment. According to Rapoport (2014), there are relationships between culture and environment as a result of changes in the context of design. For example, traditional form of building has fully responded effectively to the culture, while the modern building are found to be do not respond and do not communicate effectively to the users. Houses reflect culture, whether through everyday uses or purposeful design. House forms, such as their interior layouts, and the dwellings layout in a neighborhood can be supportive or disrupting of the culture of their inhabitants (Jabareen, 2016).

Vemuri and Costanza (2006) revealed that cultures of the low-income nations have influence on the level of the observed levels of life satisfaction, this may be attributed to dependency people have on social networks especially in developing countries like Nigeria. For example, the overall well-being of people in Nigeria is generally low and confirmed to be much lower predicted life satisfaction levels in subsequent years (Vemuri \& Costanza, 2006).

\section{Guiding principles for successful public low-cost housing in Nigeria}

\subsection{Government should regularly conduct research/ evaluation process before/ after construction of public low- cost housing}

In Nigeria, the housing programs lack vital information before and after many designed housing programs. There are important information that need to be gathered on socio-economic aspects of the users before construction of public housing schemes and after the construction certain information are also vital in giving supporting evidence which can be used to judge the performance of public housing schemes (Eziyi O. Ibem \& Amole, 2010; Makinde, 2014). 
For example, Delgado and Troyer (2017) observed that, in any housing projects apart from financial investment, users' need and preferences must be considered for a successful housing projects for low-income earners. Thus, government should ensure vital information are obtained through research so as to be used for future plan. Thus, understanding the preference of housing will help in making housing policy and framework for future housing environment especially housing for the poor (Khozaei et al., 2012).

\subsection{Encouraging designing transfer in architectural process}

The current design for public low-cost housing in Nigeria is against the culture and traditions of Nigerians. The design is more for western world that is why hardly to satisfy the beneficiaries, this is because there is a strong relationship between culture and environmental design as such cultural differences must be considered in design procedure and identification of environmental effects on people living in a particular environment(Rapoport, 2014). Architects and planners in housing can only provide adequate housing if users' needs and preferences are well understood. Jansen (2012) explained that, residential preference referred to relative attractiveness to house by individual. Therefore, should encourage change in designing from modern/western standard to traditional/local standard.

\subsection{Provision of basic infrastructure in public low-cost housing}

Most of public low-cost housing units in Nigeria have absent, little or inadequate services such as infrastructural materials like water, electricity and road which makes housing units not livable and indecent residential area (Abiodun Olukayode Olotuah, 2015; Ugonabo \& Emoh, 2013). Therefore government should provide electricity supply, road and water at existing low-cost housing by doing so, government is now reducing cost of housing production as well as improving well-being of the residents.

\subsection{Maintenance of the public low-cost housing estates and their available facilities}

Maintenance of housing units and the existing services are of great importance to the residents of the public low-cost housing. This is because, the residents' quality of life, their life satisfaction depend on the conditions and quality of housing units(Wordsworth, 2001).Most public low-cost housing are located in a bad sanitary environment. This situation make most of public low-cost housing units not livable and indecent residential (Abiodun Olukayode Olotuah, 2015; Ugonabo \& Emoh, 2013). Therefore, it is responsibility of the residents to keep the housings to the expected standard by monitoring the conditions of housing units through regular repair or maintenance of any defect identified.

\subsection{Government should implement a sound economy}

Festus and Amos (2015)revealed that lack of fund to finance the construction of houses for the low-income earners is one of the major obstacles faced by Nigerian government. There is need for government to establish a sound economy so as to ensure stable exchange rate, low interest and low inflation as suggested by(Iweala, 2014). Mukhtar, Amirudin, and Mohamad (2016) in their study explained that, implementation of favorable economic policies will encourage private sector participation in housing sector and will increase the level of affordability of residents in public low-cost housing.

\section{Significance of the study to the developing countries}

The Nigeria's experience as far as construction of low-income housing is that most of houses constructed for lowincome people are adopted from developed countries like USA and UK housing design and typology which lack social and cultural considerations. Nigeria has realized that, culture is an important element in housing because the use of space is not isomorphic across cultures. Each culture has diverse and specific variables that will have impact on space. Housing design which do not address or reflect the way of life of the people, it lead to changes in behavioral patterns and aspects of culture, which eventually have an indirect effect of the built environment on culture. In this regards, house and housing environment are regarded as the setting for privacy and part of the regulating mechanisms which facilitates privacy of the family. Therefore, if a desired level of privacy is not achieve, this will lead to redefining of privacy need and behavioral adaptation as viewed by (Abdul Rahim, 2007).

Therefore, this study is of great important to some of the developing countries. This is because the countries value construction of houses for low-income people, as they should reflect in their policies that, housing provision should not be centered towards provision of affordable housing only, but the houses should offer a design that will solve sensitive problems such as privacy, social interaction and perceptions on residential preferences and the entire lifestyle, as emphasized by (Hashim, Abu Samah, \& Ali, 2009).

\section{Conclusion}

Public Low-Cost Housing in Nigeria are considered as formal housing which assumed to have basic infrastructural facilities to cater for the residents. 
Unfortunately, majority of the residents have not satisfied with structural aspects of the housing and services provided in and around the housing units. In fact, the setup of the housing units is below the expectation of the beneficiaries. Although, there is good National Housing Policy in the country, but it has been criticized by poor implementation and lack relevance towards culture of Nigerians. Some people considered housing program in Nigeria as reflection of the of western world standard. The paper identified main problems faced by the beneficiaries of public low-cost housing in Nigeria and suggest some guiding principles that can lead to a successful construction and maintaining public low-cost housing in Nigeria.As part of limitation of this study, no field survey or interview to collect data from residents of public low-cost housing has been performed.

Therefore, in future research related to Nigerian housing sector, the research should be conducted using comprehensive methodology that comprises field survey as well as interviews with view to finds solution to public low-cost housing problems.

\section{References}

Abdul Rahim, Z. (2007). Privacy and Modification of Terrace Housing among Malay occupants in Klang, Malaysia. (Doctor of Philosophy Academic), University Putra Malaysia, Serdang.

Ajayi, J. O. (2015). The Paradox of Poverty and Inequality in Nigeria- Insights for a Post-2015 Development Agenda Scientific Papers Series Management, Economic Engineering in Agriculture and Rural Development, 15(3), 25-34.

Akinyode, B. F., Khan, T. H., \& Ahmad, A. S. (2015). Socio-Economic Factors in Measuring the Demand for Residential Neighbourhood in Nigeria. Asian Social Science, 11(12). doi:10.5539/ass.v11n12p235

Asiyanbola, R., Raji, B., \& Shaibu, G. (2012). Urban liveability in Nigeria- A pilot study of Ago- Iwoye and Ijebu-Igbo in Ogun State. Journal of Environmental Science and Engineering, 1203-1213.

Australia, L. H. (2012). Livable housing design guidelines. Sydney: Livable Housing Australia.

Ayoola, A., \& Amole, D. (2014). The Value of Housing among the poor in Ilesa, Osun State Nigeria. Architecture Research, 4(1A), 45-54. doi:10.5923/s.arch.201401.06

Baur, J. W. R., \& Tynon, J. F. (2010). Small-scale urban nature parks: Why should we care? Leisure Sciences, 32(2), 195200.

Bayulken, B., \& Huisingh, D. (2015). Perceived 'Quality of Life' in eco-developments and in conventional residential settings an explorative study. Journal of Cleaner Production, 98, 253-262. doi:10.1016/j.jclepro.2014.10.096

Bishop, B. J., \& Syme, G. J. (1995). The social costs and benefits of urban consolidation: A time budget/contingent valuation approach. Journal of economic psychology, 16(2), 223-245.

Chun-Hao, L., \& Tsai, M.-C. (2013). Is the Easy Life Always the Happiest? Examining the Association of Convenience and Well-Being in Taiwan. Social Indicators Research, 117(3), 673-688. doi:10.1007/s11205-013-0392-x

Delgado, A., \& Troyer, F. D. (2017). Housing preferences for affordable social housing projects in Guayaquil, Ecuador. International Journal of Housing Markets and Analysis, 10(1), 112-139,. doi:10.1108/IJHMA-02-2016-0017

Delmelle, E. C., Haslauer, E., \& Prinz, T. (2013). Social satisfaction, commuting and neighborhoods. Journal of Transport Geography, 30, 110-116. doi:10.1016/j.jtrangeo.2013.03.006

Diener, E. D., \& Ryan, K. (2015). Subjective well-being: a general overview. South African Journal of Psychology, 39(4), 391-406.

Ebiaride, E. C., \& Umeh, O. L. (2015). Factors influencing users' satisfaction in public and private Estate in Lagos, Nigeria. ATBU Journal of Environmental Technology, 8(2), 30-41.

Eurofound. (2013). Third European Quality of Life Survey - Quality of life in Europe: Subjective well-being. Retrieved from Luxembourg:

Fadairo, G., \& Olotuah, A. O. (2013). Low-Cost Housing for the Urban Poor in Akure, Nigeria Materials and Techniques of Construction. Journal of Environment and Earth Science, 3(9), 1-10.

Festus, I. A., \& Amos, I. O. (2015). Housing Policy in Nigeria: An Overview. American International Journal of Contemporary Research, 5(2), 7.

Gooding, T. (2016). Low-income housing provision in Mauritius: Improving social justice and place quality. Habitat International, 53, 502-516. doi:10.1016/j.habitatint.2015.12.018

Hashim, A. H., Abu Samah, A., \& Ali, H. M. (2009). Urban Malays' User-Behaviour and Prespective on Privacy and Spatial Organization of housing. ArchNet International Journal of Archtectural Research, 3(1), 197-208.

Howley, P., Scott, M., \& Redmond, D. (2009). Sustainability versus liveability: an investigation of neighbourhood satisfaction. Journal of environmental planning and management, 52(6), 847-864.

Ibem, E. O., \& Amole, D. (2012). Residential Satisfaction in Public Core Housing in Abeokuta, Ogun State, Nigeria. Social Indicators Research, 113(1), 563-581. doi:10.1007/s11205-012-0111-z

Ibem, E. O., \& Amole, O. O. (2010). Evaluation of Public Housing Programmes in Nigeria A Theoretical and Conceptual Approach. The Built \& Human Environment Review, 3(1), 88-117. 
Ismail, F., Jabar, I. L., Janipha, N. A. I., \& Razali, R. (2015). Measuring the Quality of Life in Low Cost Residential Environment. Procedia - Social and Behavioral Sciences, 168, 270-279. doi:10.1016/j.sbspro.2014.10.232

Iweala, N. O. (2014). Unleashing the Housing Sector in Nigeria and in Africa. Paper presented at the 6th Global Housing Finance Conference, World Bank Headquarters, Washington, DC.

Jabareen, Y. (2016). Culture and Housing Preferences in a Developing City. Environment and Behavior, 37(1), 134-146. doi:10.1177/0013916504267640

Jansen, S. J. T. (2012). The Impact of socio-economic characteristics, objective housing quality and preference on residentil stisfaction. Delt, Netherland.

Kalu, I. E., Agbarakwe, H. U., \& Anowor, O. F. (2014). National Housing Policies and the Realization of Improved Housing for all in Nigeria: An Alternative Approach. Asian Developing Policy Review, 2(3), 14.

Khozaei, F., Ramayah, T., Hassan, A. S., \& Surienty, L. (2012). "Sense of attachment to place and fulfilled preferences, the mediating role of huosing satisfaction". Property Management, 30(3), 292-310.

Leby, J. L., \& Hashim, A. H. (2010). Liveability Dimensions and Attributes: Their Relative Importance in the Eyes of Neibourhood Residents. Journal of Construction in Developing Countries, 15(1), 67-91.

Lee, S.-J., Kim, D., Parrott, K. R., Giddings, V. L., \& Robinson, S. R. (2017). Perceptions on residential environments for urban low-income elderly homeowners aging in place. Housing and Society, 44(1-2), 4-21. doi:10.1080/08882746.2017.1384992

Li, C., Sun, L., \& Jones, P. (2012). Liveability of High-rise Housing Estates A Resident-centered High-Rise Residential Environment Evaluation in Tianjin, China. Paper presented at the 48th ISOCARP Congress 2012, China.

Lukuman, M., Sipan, I., Raji, F., \& Aderemi, O. S. (2017). Sustainable livable housing: A review of what traditional urban areas residents find important. International Journal of Built Environment and Sustainability, 4(3). doi:10.11113/ijbes.v4.n3.212

Lynch, A. D., \& Kull, M. (2013). Relations Between Housing Characteristics and the Well-Being of Low-Income Children and Adolescents. American Psychological Association, 49(9), 1775-1789. doi:10.1037/a0031033

Makinde, O. O. (2014). Housing delivery system, need and demand. Environment, Development and Sustainability, 16(1), 49-69. doi:10.1007/s10668-013-9474-9

Mohit, M. A., Ibrahim, M., \& Rashid, Y. R. (2010). Assessment of residential satisfaction in newly designed public low-cost housing in Kuala Lumpur, Malaysia. Habitat International, 34(1), 18-27. doi:10.1016/j.habitatint.2009.04.002

Mohit, M. A., \& Iyanda, S. A. (2015). City Liveability and Housing in Nigeria A Case Study of Low-income Housing in Niger State. Procedia - Social and Behavioral Sciences 2(1), 1-13.

Mohit, M. A., \& Iyanda, S. A. (2017). Low-Income Housing in Nigeria: A liveability investigation. Asian Journal of Quality of Life, 2(6), 43. doi:10.21834/ajqol.v2i6.45

Mukhtar, M. M. M., Amirudin, R., \& Mohamad, I. (2016). Housing delivery problems in developing countries, a case study of Nigeria. Journal of Facilities Management, 14(4), 315-329. doi:10.1108/JFM-12-2015-0037

Nubi, O. T. (2008). Affordable housing delivery in Nigeria. Paper presented at the The South African Foundation International conference and exhibition, Cape Town.

Olotuah, A. O. (2015). Accessibility of Low-Income Earners to Public Housing in Ado-Ekiti, Nigeria. Civil and Environmental Research, 7(7), 1-7.

Olotuah, A. O. (2016). An Appraisal of Housing and Neighbourhood Quality in Residential Estates in Akure, Nigeria. Mediterranean Journal of Social Sciences, 7(3), 424-431. doi:10.5901/mjss.2016.v7n3s1p424

Panagopoulos, T., Duque, J. A. G., \& Dan, M. B. (2016). Urban planning with respect to environmental quality and human well-being. Environmental Pollution, 208, 137-144. doi:10.1016/j.envpol.2015.07.038

Pandey, R. U., Garg, Y. K., \& Bharat, A. (2014). Understanding Dependency of Livability on Socio-Economic and Demographic Parameters. International Journal of Humanities and Social Sciences, 3(1), 61-68.

Rapoport, A. (2001). Theory, culture and housing. Housing, Theory and Society, 17(1), 145-165.

Rapoport, A. (2014). On the Cultural Responsiveness of Architecture. Journal of Architectural Education, 41(1), 10-15. doi:10.1080/10464883.1987.10758460

Sirgy, M. J. (2016). Towards a New Concept of Residential Well-being Based on Bottom-Up Spillover and Hierarchy Theories. In F. Maggino (Ed.), A life Devoted to quality of Life (pp. 131-150). Blacksburg, USA: Springer.

Ugonabo, C. U., \& Emoh, F. I. (2013). The Major Challenges To Housing Development And Delivery In Anambra State Of Nigeria. Civil and Environmental Research, 3(4), 20.

Ukoha, O. M., \& Beamish, J. O. (1997). Assessment of residents' satisfaction with public housing in Abuja, Nigeria. Habitat International, 21(4), 445-460.

Vemuri, A. W., \& Costanza, R. (2006). The role of human, social, built, and natural capital in explaining life satisfaction at the country level: Toward a National Well-Being Index (NWI). Ecological Economics, 58(1), 119-133. doi:10.1016/j.ecolecon.2005.02.008

White, G. F., \& Schollaert, P. T. (1993). Home ownership and well-being. Housing and Society, 20(1), 31-40.

Wordsworth, P. (2001). Lee's Building Maintenance Management (4th ed.). London: Blackwell Science. 